\title{
Edina Goes Green Part III: A Survey of Consumer Lawn Care Knowledge and Practices
}

\author{
Perrin J. Carpenter and \\ $\mathrm{M}$ ary $\mathrm{H}$ ockenberry $\mathrm{M}$ eyer
}

ADDITIONAL INDEX WORDS. environmental attitudes, community education, consumer horticulture, pesticides

Summary. H omeowners in E dina, M inn., were surveyed in conjunction with a low-input lawn care community educa tion project. Surveys were sent at the start and finish of the yearlong project, and asked questions pertaining to the respondent's lawn care knowledge, practices, and environmental attitude toward lawn inputs. The responses from before the program, compared with those afterward, show overall that homeowners lawn care did not change significantly by the end of the educational campaign. Responses are useful, however, in targeting future educational efforts. For example, while $>\mathbf{8 0} \%$ of respondents were aware of the benefits of leaving mowed clippings on the lawn, $<6 \% \mathrm{knew}$ how much fertilizer is needed yearly for a medium maintenance lawn. Participants indicated a $10 \%$ weed tolerance was acceptable, but $\mathbf{2 5 \%}$ was not; and disagreed with the statement "pesticides are not harmful to the environment."

D epartment of H orticultural Science, U niversity of M innesota, St Paul, 55108.

$M$ innesota Experiment Station scientific journal series paper 981210037 . The cost of publishing this paper was defrayed in part by the payment of page charges. U nder postal regulations, this paper therefore must be hereby marked advertisement solely to indicate this fact. 
awn care is a major gardening activity in the U nited States ( $N$ ational Gardening Association, 1997) and has increasingly become a target for environmentalists (Stein, 1993). M any homeowners see aesthetic and social value in a green, attractive, well-maintained lawn (J enkins, 1994). Concerned citizens of E dina, $M$ inn., a suburb of $M$ inneapolis, raised questions about pesticide safety with children in public parks. In recent years, public attitudetoward pesticideshas becomean issueamong communities and government, (Star Tribune, 1994) with consumer use of pesticides steadily declining since the 1980s (A spelin, 1997; M . D ana, personal communication). $\mathrm{E}$ dina residents teamed up with $\mathrm{C}$ ity $\mathrm{H}$ all and the $\mathrm{U}$ niversity of $M$ innesota Extension Service to develop an educational campaign, called E dina G oes G reen (EGG), aimed at teaching environmentally responsible low-input home lawn care techniques (Carpenter and M eyer, 1999a).

E dina has a population of $\approx 46,000$ with an estimated 15,000 owner-occupied households. The city estimates that $\approx 600$ acres $(243 \mathrm{ha})$ of public and 4,850 acres $(1,963)$ of privateland are planted with turfgrass. In 1990, the median familyincomewas $\$ 64,127$, household incomewas $\$ 48,936$ (South H ennepin Regional Planning Agency, 1993).

This paper reports the results of two surveys of Edina residents, one at the beginning and a second at end of the educational campaign. The objectives of the surveys were to measure lawn care knowledge and practices; environmental attitudes toward lawn care; and the effectiveness of the educational program.

The surveysused in this study were developed based on other research, ( $M$ innesota Center for Survey Research, 1995; V irginia C ooperative Extension Service, 1985; M orris and Traxler, 1996) and were distributed to a random sample of Edina households. All surveys were mailed, followed by a reminder postcard and then a second survey was sent to nonrespondents. The first survey was mailed in $\mathrm{M}$ ay 1996 before the majority of the educational campaign, to 800 households with 549 (68.6\%) returned. In M ay 1997, after the educational campaign, a second survey was mailed to these same households, with 466 (58\%) returned. The surveys were identical with the exception of two additional questions in the second survey, which asked about familiarity with theE GG program, and itsvarious educational tools. Chi-squared distribution tests were used to compare the responses.

\section{Lawn care knowledge and practices}

Examining the survey responses provides insight into which lawn care concepts E dina residents al ready seem to understand, and which concepts were still misunderstood even after the educational campaign ( $T$ able 1 ).

Responses to questions 3 and 6 concerning lawn clippings knowledge and practices show the majority of residents' knowledge and practices were in accordance with EGG's recommendations both before and after the educational campaign. M ost respondents to question 3 recognize that leaving grass clippings on the lawn is beneficial. $\mathrm{H}$ owever, 20\% were still bagging clippings after the educational campaign. Since most respondents indicated on question 6 that they do leave their clippings on the lawn, this is apparently one case in which the lawn care knowledge and practices were in synch.

For many of the questions in Table 1, the frequencies of responses were similar before and after the educational campaign, but most responses in each case were not necessarily in accordance with EGG's teachings. During the educational campaign EGG emphasized fall as the best time to control perennial broadleaf weeds, but most respondents from either survey chose spring for this question. O nly a slight increase, $2.4 \%$ for a total of $8.8 \%$ indicated that fall was preferred for weed control in the second survey.

When and how much to fertilize the lawn was another commonly misunderstood concept. For question 1 , most respondents indicated that fall was the best time to fertilize the lawn. This is the "correct" response, and seems encouraging, except that almost as many respondents indicated that spring was the best time to fertilize. When asked in question 7 when they actually apply fertilizer to the lawn, most respondents werestill fertilizing in the spring, with fall a close second.

M ost responses to question 4, how much fertilizer was needed for a medium maintenancelawn, was "don't know". U niversity of M innesota Extension Service publications recommend that medium maintenance lawns receive two fertilizer treatments, each with $1 \mathrm{lb}$ of nitrogen/ $1000 \mathrm{ft}^{2}$ per year, and both applied in the fall (M ugaas, 1995). Since there was no significant increase in the number of respondents at the end of the program who knew how much fertilizer to use on the lawn, this is clearly another key area to emphasis in future educational efforts. Our findings concerning the lack of fertilizer know-how in Edina are supported by results from other fertilizer use studies in the $\mathrm{T}$ win Cities which concluded that homeowners generally are not following recommendations of turfgrass specialists regarding fertilizer use (C reason and Runge, 1992; Schultz and Cooper, 1995).

Another practice not in synch with low input practices was mowing height, at the end of the program $34 \%$ were mowing at 1-2 inches, rather than the recommended 2-3 inches.

\section{Environmental attitudes}

Environmental attitudes toward lawn care are presented in T able 2, showing very consistent responses to both surveys for all questions. M ost respondents indicated some degree of weed tolerance, although $10 \%$ seemed to be the usual limit of acceptance. M ost respondents viewed pesticides and, to a lesser extent, fertilizers, as potentially harmful to the environment and public health. This agrees with public opinion of pesticides in commercial agriculture (van Ravenswaay, 1995). Respondents favor posting signs in public parks whenever either of these inputs is used. M ost also favor posting signs on private property whenever pesticides are applied, but fewer think that signs are necessary when fertilizer is used. $\mathrm{N}$ early all respondents agreed that a well-kept lawn increases property values, but most disagreed that the lawn was more important than the house's exterior appearance or the presence of shade trees.

$O$ verall, five of the questions had significant differences in responses between the first and second surveys. U nfortunately, these questions were not necessarily linked or relevant to the EGG program. T wo questions: " $\mathrm{H}$ ow often do you water your lawn?" and "I am satisfied with my lawns appearance" probably differed the second year because a summer drought occurred. Three other questions, "H ow often do you mow your lawn?", "H ow short do you usually 


\section{Survey}

question

The single best time to fertilize a lawn is

Spring

Summer

Fall

Don't know

The single best time to control broadleaf weeds is

Spring

Summer

Fall

Don't know

L awn clippings are

D etrimental to the lawn

Of no value to the lawn

Equal to 1 fertilizer treatment

D on't know

The amount of fertilizer needed for a medium maintenance lawn is

$1 \mathrm{lb} \mathrm{N} / 1000 \mathrm{ft}^{2}$ per yr

$2 \mathrm{lb} \mathrm{N} / 1000 \mathrm{ft}^{2}$ per yr

$3 \mathrm{lb} \mathrm{N} / 1000 \mathrm{ft}^{2}$ per yr

$5 \mathrm{lb} \mathrm{N} / 1000 \mathrm{ft}^{2}$ per yr

$\mathrm{N}$ one

Don't know

Which of the following pests usually require control in M innesota home lawns? (circle all that apply)

Insects

Weeds

$D$ iseases

Don't know

M y lawn clippings are usually

Left on the lawn

Put on compost pile

Bagged and removed

Don't know

M y lawn is usually fertilized in the: (circle all that apply)

Spring

Summer

Fall

$\mathrm{N}$ ever

D on't know

What pesticides do you currently use on your lawn? (circle all that apply)

$\mathrm{H}$ erbicide

Insecticide

Fungicide

O ther

$\mathrm{N}$ one

Don't know

H ow often do you usually water your lawn?

O ften

Regularly

O nly when dry

$\mathrm{N}$ ever

D on't know

H ow often do you usually mow your lawn?

$>1$ / week

1/ week

$<1 /$ week

O nly when long

D on't know

H ow short do you usually mow your lawn?

$\leq 1$ inch

1 to 2 inches

2 to 3 inches

3 to 4 inches

$>4$ inches

Don't know
F requency (\%)

B efore

After

42.3

1.6

45.5

7.1

0.9

52.1

78.3

5.8

78.3

6.4

5.8

8.2

8.8

5.8

2.7

3.0

3.3

79.6

13.8

83.7

10.7

4.9

4.6

2.2

1.3

75.8

18.0

82.3

30.4

11.7

66.3

6.4

23.5

0

79.2

35.0

61.9

9.8

1.5

64.8

5.6

6.0

0.9

20.0

13.1

14.6

17.3

60.8

5.8

0.5

12.9

68.3

5.5

11.7

0.2

0

31.1

51.0

12.8

0.2

4.0
9.7

13.5

6.7

5.2

2.1

1.5

68.9

21.9

81.5

32.8

10.5

69.3

5.8

20.0

0

81.3

34.5

68.2

7.3

0.6

60.3

5.2

6.4

3.4

21.9

14.2

16.7

31.8

47.0

2.4

0

8.2

70.2

7.1

13.1

0

1.3

34.1

48.7

10.5

0.6

2.4

Hor lechnology • J uly-September 1999 9(3) 
T able 2. B efore and after E G G educational campaign survey responses to statements related to the environmental impact of lawns. Average rankings are on a scale of 1 to 4 , where 1 = strongly agree, 2 = agree, 3 = disagree, $4=$ strongly disagree.

\begin{tabular}{lcc} 
Survey & \multicolumn{2}{c}{ Average rank } \\
\cline { 2 - 3 } question & B efore & After \\
\hline Some weeds (10\%) are okay in my lawn & 2.19 & 2.14 \\
M ore weeds (25\%) are okay in my lawn & 3.23 & 3.20 \\
N o weeds are my goal & 2.49 & 2.55 \\
A s long as my lawn is green, it's okay & 2.55 & 2.62 \\
Pesticides are not harmful to the environment & 3.32 & 3.31 \\
Pesticides are not harmful to public health & 3.32 & 3.35 \\
Fertilizers are not harmful to the environment & 2.97 & 3.01 \\
Fertilizers are not harmful to public health & 2.89 & 2.93 \\
I am satisfied with my lawn's appearance & 2.13 & 2.29 \\
A well-kept lawn increases property values & 1.65 & 1.66 \\
A green, weed-free lawn is more important than my house being painted & 3.21 & 3.22 \\
A green, weed-free lawn is more important than shade trees around my house & 3.17 & 3.20 \\
Signs should be posted on public parks whenever fertilizer is applied & 1.76 & 1.72 \\
Signs should be posted on public parks whenever pesticides are applied & 1.56 & 1.51 \\
H omeowners should be required to post signs on their property whenever fertilizer is applied & 2.30 & 2.23 \\
H omeowners should be required to post signs on their property whenever pesticides are applied & 2.04 & 1.98 \\
O rganic lawn care products are just as effective as inorganic products & 2.12 & 2.16
\end{tabular}

mow your grass?", and "Pesticides are not harmful to the environment", differed in proportion of total responses, due to a lower number of the second surveys returned. In each of thesefive questions, most responses remained the samein both surveys.

\section{Conclusions}

The overall similarity in responses to surveys distributed at the start and end of the educational campaign indicates that there was little change in the lawn care knowledge, practices, or environmental attitudes of Edina residents during the yearlong program. In some areas, such as management of grass clippings, this may be because positive practices were al ready adopted in the community. In other areas, such as knowing when and how much to fertilize the lawn, results indicate that further education is needed.

Edina residents, similar to other consumers, are concerned about the environmental impact of lawn pesticides and fertilizers. The majority see pesticides as harmful to the environment and support posting where pesticides and fertilizers have been used. Although they acknowledge the potential harm to the environment, they appear unsure of the proper amount and time for fertilizer application; and most will not tolerate $25 \%$ weeds in their lawn. 0 ur findings suggest that repetitive, long-term education, using a variety of tools, and emphasizing key areas as determined by survey results, are necessary for impacting consumer changes in lawn care.

\section{Literature cited}

A spelin, A.L. 1997. Pesticides industry sales and usage: 1994 and 1995 market estimates. U.S. EPA, Wash., D.C.
Carpenter, P.J . and M.H . M eyer. 1998. Edina goes green part I: A model for low-input lawn care community education. $H$ ortTechnology 9(3):486-489.

Creason, J.R. and C.F. Runge. 1992. U se of lawn chemicals in the Twin Cities. U niv. M inn. (St. Paul) Water Resources Res. Ctr. Public Rpt. Ser. 7.

Jenkins, V. Scott. 1994. The lawn: A history of an American obsession. Smithsonian Inst., Wash., D.C.

Kaszuba, M. 1994. E dina shelves use of herbicides, but no trend in making. M inneapolis Star T ribune, Sunday, 7 Aug.

M innesota Center for Survey Research. 1995. Lawn care survey and focus groups: Results and technical report. U niv. M inn. (M inneapolis) Tech. Rpt. 95-25.

M orris, B. and D. Traxler. 1996. D akota county subwatersheds residential survey on lawn care and water quality. D ecision Resources, Ltd., M inneapolis, M inn.

M ugaas, R. 1995. LIL aC: low-input lawn care. U niv M inn. Ext. Serv. M etro Cluster.

N ational Gardening Association. 1997. 1997-98 National gardening survey. Burlington, $\mathrm{Vt}$.

Schultz, J.W. and T.H. Cooper. 1995. Fertilizing Twin Cities' lawns. CURA Rpt. 25:6-9.

South H ennepin Regional Planning Agency. 1993. D emographic, economic, and social trends affecting peopleof Edina. S. H ennepin Reg. Planning Agency H uman Serv., E dina, M inn.

Stein, S. 1993. N oah's garden. H oughton M ifflin C o., N ew York. van Ravenswaay, E.O . 1995. Public perceptions of agrichemicals. Council Agr. Sci. Technol., Ames, Iowa.

Virginia C ooperative Extension Service. 1985. Survey of Virginia homeowner preferences in lawn care. Proc. 24th Va. Turfgrass Conf. Trade Show. p. 39-42. 